\title{
Procesos y dinámicas en el espacio geográfico de España
}

\author{
Aaron Gutiérrez'
}

La grave crisis económica que afronta España desde 2008 está derivando en profundos cambios sociales, políticos y económicos. Éstos, a su vez, se presentan distintos comportamientos en diferentes escalas territoriales. La crisis hipotecaria, la proliferación de proyectos urbanísticos fallidos o el cambio de los flujos migratorios son algunas de las manifestaciones, no solo de la crisis, sino también de las implicaciones derivadas del modelo de desarrollo neoliberal y centrado en la rentabilidad a corto plazo imperante en las décadas precedentes. Las múltiples y profundas problemáticas relacionadas con la vivienda se han convertido en una de las manifestaciones más evidentes de todo ello. Se puede ejemplificar a partir de la paradoja que mientras centenares de miles de personas han perdido su vivienda fruto de la ola de ejecuciones hipotecarias y desahucios, también se ha alcanzado el record de vivienda vacía, fruto de la hipertrofia inmobiliaria de los años de la "burbuja".

Tres artículos de este monográfico abordan la cuestión de los desahucios. Constituyendo así, una colección inédita que permite una lectura geográfica de la crisis hipotecaria y los desahucios en España.

El trabajo de Ricardo Méndez Gutiérrez del Valle desarrolla una lectura geográfica de las ejecuciones hipotecarias en el conjunto del territorio español. El trabajo utiliza datos oficiales relativos a ejecuciones hipotecarias provenientes del Consejo General del Poder Judicial agregados por partidos judiciales (431 partidos que cubren todo el territorio español). Los resultados permiten evidenciar, en primer lugar, el colosal crecimiento de las ejecuciones hipotecarias a través de la comparativa del período 2008-2014 en relación con el 2001-2007. En segundo lugar, detallan la desigual geografía de la desposesión de vivienda en España en el período 2008-2014. El autor apunta dos variables clave para interpretar las pautas territoriales de este fenómeno: la vulnerabilidad territorial y la exposición a la "burbuja inmobiliaria".

Aaron Gutiérrez y Antoni Domènech se centran en las viviendas acumuladas por la SAREB. Esta sociedad, que como otros "bancos malos" europeos, fue creada en el marco del rescate de la UE a la banca española. Nace con el objetivo que los bancos con problemas le transfieran sus "activos tóxicos" provenientes del sector inmobiliario. El trabajo se centra en las viviendas acumuladas por los bancos a través de desahucio vía ejecución hipotecaria y ahora transferidas a la SAREB. En total, se georeferencia más de 33.000 viviendas en el territorio español. Ello permite desarrollar un análisis en dos escalas. Para el conjunto de España se identifica que los territorios con mayor expansión inmobiliaria durante la época del boom son los que, tras la crisis, acumulan 
más vivienda en manos de la SAREB. Éstos son el sur de la región metropolitana de Madrid y el litoral mediterráneo, especialmente la Comunidad Valenciana. A escala local, se utilizan los casos de estudio de las ciudades de Alicante, Murcia y Zaragoza, para evidenciar como los desahucios por ejecución hipotecaria se han concentrado en los barrios más vulnerables. El trabajo permite demostrar como a mayor tasa de paro, presencia de población extranjera y menor nivel de ingresos, mayor concentración de viviendas desahuciadas en manos de la SAREB.

El artículo de Sònia Vives-Miró y Onofre Rullan analiza la relación entre la turistización y la desposesión de vivienda en el centro histórico de Palma de Mallorca. Se trata de un barrio de alto valor patrimonial, creciente presión turística y con una manifiesta escalada de precios de la vivienda. Partiendo de las teorías clásicas de desvaloración y revaloración urbana, gentrificación y desplazamiento de residentes, los autores exponen cómo la ola de desahucios en el barrio sienta las bases para un proceso de revalorización y generación de nuevas rentas urbanas; cerrando así el círculo de un proceso de acumulación por desposesión de vivienda vía desahucios. A partir de datos relativos a la evolución de los precios de la vivienda, la localización de los desahucios y la creación de nuevos alojamientos turísticos, el artículo dibuja las coincidentes geografías de la desposesión, revalorización y turistización en el barrio. Aporta un ejemplo ilustrativo de cómo la turistización de determinadas ciudades del mediterráneo contribuye a acelerar los procesos de financiarización del entorno construido y la mercantilización de la vivienda inherentes a la producción de la ciudad capitalista.

Continuado con las implicaciones del modelo inmobiliario y urbanístico español, Víctor Jiménez Barrado, Carmen Delgado Viñas y Antonio-José Campesino Fernández presentan los efectos que la desregulación urbanística de los terrenos en suelo rústico y no urbanizable, en las regiones de Cantabria y Extremadura. Los autores subrayan como, después de dos décadas de urbanismo expansivo, la inacción de los gobiernos regionales, junto con la permisividad de la legislación, han acabado por facilitar que los crecientes procesos de dispersión urbana hayan derivado en la proliferación construcción residencial irregular en suelo no urbanizable. Se tratan de espacios próximos a las áreas urbanas, atractivos por sus valores asociados con la ruralidad y la calidad ambiental que, a su vez, ofrecen altas rentabilidades. Esto deriva en el alza del precio del suelo, en una espiral especulativa que conlleva que las rentas agrarias no puedan competir con las expectativas de las rentas de inversión inmobiliaria. Ello contribuye al abandono de la función productiva de estos espacios y a la degradación de sus valores ambientales. El trabajo también apunta directrices que permitan frenar este proceso de depredación del territorio.

El artículo de Alberto Capote y José Antonio Nieto Calmaestra estudia la evolución de la población escolar extranjera en el período 2008-2014. Durante la década del boom económico (19972006) España se convirtió en el principal receptor de población extranjera de la UE. Con la crisis económica, esta situación ha cambiado drásticamente, llegándose a registrar saldos negativos. Todo ello se refleja en el ámbito educativo. En un período breve se produjo un rápido crecimiento de los alumnos de procedencia extranjera en los centros escolares. A partir de la crisis la disminución ha sido de intensidad moderada y concentrada especialmente en los jóvenes provenientes de América Latina. Se constata que la distribución de estudiantes extranjeros por provincias, pese a presentar una mayor concentración en las zonas urbanas, evidencia una implantación relevante en zonas rurales. Por otra parte, aunque se constatan diferencias entre provincias, la abrumadora mayoría de los jóvenes extranjeros son escolarizados en centros públicos. Ello les haces más sen- 
sibles a las políticas de austeridad y recortes que han sufrido los centros de enseñanza pública desde el inicio de la crisis.

Cayetano Espejo Marín, Ramón García Marín y Ana Eulalia Aparicio Guerrero analizan la evolución de la energía minihidráulica desde mediados del siglo XX a la actualidad. A partir de los datos de energía instalada y generada los autores evidencian un repunte de este tipo de producción energética, como ya sucedió a partir de la crisis del petróleo en la década de 1970. El artículo destaca el rol estratégico de la legislación en el desarrollo reciente de la red de producción. Ley del Sector Eléctrico del 1997 permitió el desarrollo de las energías renovables, y la minihidráulica en particular. Mientras que la Ley del Sector Eléctrico de 2013 abandona el modelo anterior e introduce nuevas incertidumbres sobre su viabilidad económica. Esta incertidumbre sumada a las barreras burocráticas y los conflictos asociados al uso del agua en España derivan en un nuevo contexto de regresión de este tipo de producción energética.

El último artículo relacionado con los procesos y dinámicas que ocurren en el espacio geográfico español es elaborado por José Ignacio García-Valdecasas y Iván López. En este trabajo, los autores exponen la relevancia de los modelos basados en agentes para el análisis de la segregación étnica espacial urbana. El texto parte del modelo de Schelling desarrollado durante la década de 1970, y propone nuevos supuestos de revisión del mismo. Desarrolla experimentos virtuales, para analizar cómo influye la densidad de población en la segregación étnica espacial urbana. Los resultados permiten concluir que, aunque no tiene un comportamiento lineal, a mayor densidad, tamaño del vecindario e intolerancia, más intensa es la segregación. A partir de estas evidencias se plantea la utilidad de resultados conseguidos con los experimentos virtuales para el estudio de fenómenos sociales.

Junto con estos siete artículos, se publican otros tres artículos que abordan diversas temáticas. El primero de ellos, de Gisela Aquino Pires do Rio y Leo Name, trata del proceso de patrimonialización de espacios y recursos naturales en el área transfronteriza entre Brasil, Argentina y Paraguay, en la región que se conoce como Alto Paraná, donde existe un área urbana continua formada por las ciudades de Foz do Iguaçu (en el estado de Paraná, Brasil), Puerto Iguazú (en la provincia de Misiones, Argentina) y Ciudad del Este (capital del departamento Alto Paraná, Paraguay). Concluyen que en la legislación basada en la escala de cada uno de los países involucrados no se han diseñado dispositivos que posibiliten sincronía y simetría de acciones con miras a la protección ambiental conjunta, situación que podría mejorar si se transitara hacia la figura de las Áreas Protegidas Transfronterizas como categoría específica de zonas de fronteras, tal como ocurre en otros lugares del Mundo.

Los geógrafos Johannes Rehner y Sebastián Rodríguez-Leiva, plantean una discusión en dos escalas geográficas, en primer lugar, reflexionan sobre la financiarización en Chile y sus regiones, en relación con la actividad exportadora. En segundo lugar, se plantea un cambio de escala, estimando la inversión inmobiliaria presupuestada mediante modelos de regresión para la ciudad de La Serena localizada en el norte de Chile. Basados en el análisis de la situación a escala país demuestran cómo la liquidez financiera, el ahorro de los hogares y el otorgamiento de los créditos en Chile se asocian a los ciclos de auge y crisis, recuperación y estagnación. En tanto, a escala de ciudad, las tendencias muestran que la inversión inmobiliaria en La Serena está dada en gran medida por los flujos de capitales provenientes de la exportación y el sistema financiero, pero que 
la inversión inmobiliaria no muestra relación estadísticamente significativa con el otorgamiento de créditos hipotecarios, lo que permite deducir que el crecimiento urbano de la ciudad no está dado por el endeudamiento de los hogares.

En tanto, el texto de Adriana María Otero, Hugo Marcelo Zunino y Mariana Rodríguez, indaga sobre las tecnologías socioculturales desplegadas por migrantes por estilo de vida en la ciudad de Pucón (sur de Chile) y examina en qué medida ellas contribuyen a un proceso de innovación sustentado en el intercambio cultural entre los migrantes y los habitantes de las comunidades receptoras desde la visión de los migrantes emprendedores. A través de la realización de 12 entrevistas en profundidad a migrantes que recientemente se han asentado en la localidad y que han iniciado procesos de innovación, concluyen que las tecnologías socioculturales para la innovación son producto de la emergencia de lo nuevo como acumulación histórica de horizontes y prácticas de los grupos involucrados, migrantes de amenidad/por estilos de vida y pobladores locales.

Por último, queremos indicar que en este número también se publican dos reseñas de libros. Gabriela Inés Maldonado, presenta el texto "Riesgos, catástrofes y vulnerabilidades. Aportes desde la Geografía y otras Ciencias Sociales" para casos argentinos, editado por Claudia E. Natenzon y Diego Ríos. Por su parte, Obdulia Monteserín-Abella, reseña el libro “Patrimonio Cultural y Desarrollo Territorial. Cultural Heritage \& Territorial Development", coordinado por Fernando Manero Miguel y José Luis García Cuesta. 